\title{
Production, carcass characteristics and valuable cuts of beef breed bulls and heifers in Finnish beef cattle population
}

\author{
Maiju Pesonen and Arto Huuskonen \\ Natural Resources Institute Finland (Luke), Green Technology, Fl-92400 Ruukki, Finland \\ e-mail: maiju.pesonen@luke.fi
}

\begin{abstract}
The objective of the present study was to determine growth and carcass traits of beef breed bulls and heifers in the Finnish beef cattle population. The data collected from Finnish slaughterhouses included observations of 6323 and 2385 Hereford (bulls and heifers, respectively), 4421 and 1794 Charolais, 4335 and 1951 Limousin, 4068 and 1692 Aberdeen Angus, 2151 and 774 Simmental, 344 and 147 Blonde d'Aquitaine animals. For estimating valuable cuttings, a separate dataset including in total 1112 bulls and 260 heifers was also collected. Significant breed differences were observed in growth performance, carcass traits and retail product yield. The later maturing, Continental beef breeds seem to reach higher carcass gains, produce less fat and have more valuable cuts than the earlier maturing British beef breeds. The later maturing beef breeds tend to have carcass traits that suit well in the Finnish beef production system.
\end{abstract}

Key words: beef production, bulls, heifers, breeds, growth, muscle characteristics

\section{Introduction}

Beef production in Finland is mostly based on the dairy breeds (Niemi and Ahlstedt 2014). However, the decrease in the dairy cattle population observed in recent years threatened to reduce the level of beef production, and production from beef breed calves is increasing at present. Because of the falling supply of domestic beef, there is nowadays a clear discrepancy between the demand for and supply of domestic beef. For example in 2013, beef production was 80.3 million kg whereas consumption was 98.2 million kg (Niemi and Ahlstedt 2014). Consequently, slaughterhouse pricing favours heavy carcasses and the average carcass weights of slaughtered animals have clearly increased during recent years. For instance, the average carcass weight of slaughtered bulls (including both dairy and beef breeds) increased from $275 \mathrm{~kg}$ (2000) to $336 \mathrm{~kg}$ (2013) in thirteen years (Niemi and Ahlstedt 2014). However, the current situation is complicated because fatness generally increases with higher carcass weight (Keane and Allen 1998) and, on the other hand, market demand in Finland concerning carcass fat is different from those beef markets where marbled beef is favoured (Herva et al. 2011). Consumers generally favour low-fat products in Finland, and the beef industry has stated that optimally two thirds of the carcasses would have a EUROP fat score of 2 and one third a EUROP fat score of 3 (Herva et al. 2011). Lean carcasses are favoured in setting prices. There are penalties for carcasses under $320 \mathrm{~kg}$ with fat scores 3-5 and for carcasses over $320 \mathrm{~kg}$ with fat scores 4-5.

Carcass composition largely determines carcass value. A high proportion of muscle with an optimum level of fat dictated by local consumer preferences represents a superior carcass. Differences between individual beef breeds in growth performance and carcass traits have been extensively evaluated earlier, for example, by Bartoň et al. (2006), Cuvelier et al. (2006a,b), Alberti et al. (2008) and Pesonen et al. (2012, 2013a,b). However, the amount of experimental animals is often limited when growth and carcass characteristics of different breed groups are compared. Consequently, there is a concern about the representativeness of the experimental animals compared with other animals from the same breed groups, i.e. whether they represent the whole variation in their respective populations. In addition, breed comparisons are mainly relevant for their specific production conditions and genetic level. Therefore, the main objective of the present research based on a dataset collected from slaughterhouses was to study growth and carcass traits of beef breed bulls and heifers in Finnish beef cattle population. The second objective was to evaluate carcass fat score in relation to carcass weight in different breed groups.

\section{Materials and methods Dataset - complete slaughter data}

Dataset used for studying growth and carcass characteristics was collected from four Finnish slaughterhouses (Atria Ltd., Seinäjoki, Finland; HK-Agri Ltd., Turku, Finland; Saarioinen Lihanjalostus Ltd., Tampere, Finland, and Snellman Lihanjalostus Ltd., Pietarsaari, Finland). These slaughterhouses are major meat companies in Finland, which, as a part of their business operations, transfer calves from dairy farms, or suckler cow herds, to co-operating farms for fattening prior to slaughter.

Manuscript received May 2015 
The raw slaughter data for each animal included individual animal identification number on ear tag, date of birth, date of slaughter, sex, carcass weight, carcass conformation score (EUROP) and carcass fat score (EUROP). Identities of breeds (dam and sire breed) were collected from the National Animal Identification Register for Cattle (ProAgria Agricultural Data Processing Centre, P.O. Box 25, FI-01301 Vantaa, Finland). Slaughtering data and identities of breeds for individual animals were linked through individual animal identification numbers. All purebred Aberdeen Angus ( $\mathrm{Ab}$ ), Blonde d'Aquitaine (Ba), Charolais (Ch), Hereford (Hf), Limousin (Li) and Simmental (Si) bulls aged 365-730 days old and heifers aged 240-600 days old which were slaughtered by above-mentioned slaughterhouses during 2009-2011 were selected for the study.

In all slaughterhouses the carcasses were weighed hot after slaughter and the cold carcass weight was estimated as 0.98 of the hot carcass weight. The carcasses were classified for conformation and fatness using the EUROP quality classification (EC 2006). For conformation, development of carcass profiles, in particular the essential parts (round, back, shoulder), was taken into consideration according to the EUROP classification (E: excellent, U: very good, R: good, O: fair, P: poor), and for fat cover, the amount of fat on the outside of the carcass and in the thoracic cavity was taken into account using a classification range from 1 to 5 (1: low, 2: slight, 3: average, 4: high, 5: very high). Each level of the conformation scale was subdivided into three sub-classes (e.g. O+, O, O-) to produce a transformed scale ranging from 1 to 15, with 15 being the best conformation.

Birth weight assumptions used in calculations were 38, 47, 49, 42, 43 and $46 \mathrm{~kg}$ live weight for $\mathrm{Ab}, \mathrm{Ba}, \mathrm{Ch}, \mathrm{Hf}$, Li and Si bull calves, respectively, and 36, 44, 46, 40, 41 and $44 \mathrm{~kg}$ for heifer calves, respectively (Åkerlind et al. 2011). Birth carcass weight was assumed to be $0.4 \times$ birth weight since the same value was used by Atria Ltd. in daily extension work (Herva et al. 2009, 2011). An estimated daily carcass gain was calculated by subtracting birth carcass weight from the reported slaughter weight and dividing the result by age at slaughter. The complete final slaughter data comprised 21364 slaughtered bulls and 8743 slaughtered heifers; the average slaughter age was 567 and 461 days and the mean carcass weight 386 and $242 \mathrm{~kg}$ for the bulls and heifers, respectively (Table 1). The average estimated daily carcass gain was 656 and $497 \mathrm{~g} \mathrm{~d}^{-1}$, the EUROP conformation score 8.2 and 6.0 and the carcass fat score 2.7 and 3.4 for the bulls and heifers, respectively.

Table 1. Description of the experimental data

\begin{tabular}{|c|c|c|c|c|c|c|c|c|c|c|}
\hline \multirow[b]{2}{*}{ Dataset, complete slaughter data } & \multicolumn{5}{|c|}{ Bulls } & \multicolumn{5}{|c|}{ Heifers } \\
\hline & $\mathrm{n}$ & Mean & SD & $\mathrm{q}_{0.05}$ & $\mathrm{q}_{0.95}$ & $n$ & Mean & SD & $\mathrm{q}_{0.05}$ & $\mathrm{q}_{0.95}$ \\
\hline Age at slaughter, $d$ & 21634 & 567 & 57.8 & 465 & 650 & 8743 & 461 & 54.4 & 366 & 541 \\
\hline Carcass gain, $\mathrm{g} \mathrm{d}^{-1}$ & 21634 & 656 & 113.7 & 472 & 844 & 8743 & 497 & 86.2 & 353 & 636 \\
\hline Carcass weight, kg & 21634 & 386 & 62.8 & 281 & 485 & 8743 & 242 & 38.5 & 180 & 304 \\
\hline Conformation score & 21610 & 8.2 & 2.29 & 5 & 13 & 8741 & 6.0 & 1.65 & 4 & 9 \\
\hline Fat score & 21634 & 2.7 & 0.97 & 1 & 4 & 8743 & 3.4 & 1.02 & 2 & 5 \\
\hline \multicolumn{11}{|l|}{ Dataset, commercial cutting } \\
\hline Age at slaughter, $d$ & 1112 & 575 & 53.7 & 484 & 649 & 260 & 485 & 47.8 & 399 & 546 \\
\hline Carcass gain, $\mathrm{g} \mathrm{d}^{-1}$ & 1112 & 628 & 114.9 & 431 & 827 & 260 & 468 & 75.0 & 358 & 605 \\
\hline Carcass weight, kg & 1112 & 376 & 67.0 & 262 & 482 & 260 & 241 & 35.1 & 182 & 299 \\
\hline Conformation score & 1112 & 8.0 & 2.26 & 5 & 12 & 260 & 6.4 & 1.64 & 4 & 9 \\
\hline $\begin{array}{l}\text { Fat score } \\
\text { From carcass yield, } \mathrm{g} \mathrm{kg}^{-1}\end{array}$ & 1112 & 2.6 & 0.82 & 2 & 4 & 260 & 3.3 & 0.92 & 2 & 5 \\
\hline Subcutaneous fat & 1112 & 42 & 17.8 & 18 & 75 & 260 & 61 & 25.5 & 26 & 106 \\
\hline M. longissimus & 1069 & 41 & 4.5 & 34 & 48 & 250 & 42 & 5.0 & 34 & 50 \\
\hline M. psoas major & 1069 & 14 & 1.5 & 12 & 17 & 249 & 16 & 1.6 & 13 & 18 \\
\hline M. semimembranosus & 1076 & 40 & 5.0 & 33 & 48 & 252 & 44 & 6.0 & 35 & 54 \\
\hline M. semitendinosus & 1080 & 65 & 7.1 & 55 & 77 & 253 & 65 & 8.5 & 53 & 79 \\
\hline M. quadriceps femoris & 1093 & 36 & 3.4 & 31 & 41 & 254 & 40 & 4.2 & 33 & 46 \\
\hline M. gluteus medius & 1096 & 19 & 2.3 & 15 & 22 & 257 & 20 & 3.0 & 15 & 24 \\
\hline
\end{tabular}

$\mathrm{SD}=$ Standard deviation; 0.05 -quantile (approximately $5 \%$ of the data has a value less than the 0.05 -quantile); 0.95-quantile (approximately $95 \%$ of the data has a value less than the 0.95 -quantile); Conformation score: $(1=$ poorest, $15=$ excellent); Fat score: $(1=$ leanest, $5=$ fattest); Musculus longissimus = loin; Musculus psoas major = tender loin; Musculus semimembranosus = inside round; Musculus semitendinosus = outside round; Musculus quadriceps femoris = corner round; Musculus gluteus medius = roast beef 


\section{Dataset - commercial cutting}

For estimating valuable cuttings for studied breeds a separate dataset was collected during 2010-2011 from Snellman Lihanjalostus Ltd. In addition to above-mentioned variables this dataset included also information of commercial cuttings. After classification the carcasses were chilled overnight below $7{ }^{\circ} \mathrm{C}$. On the day after slaughter the carcasses were commercially cut. Each carcass was cut into valuable cuts (outside round (Musculus semitendinosus), inside round (Musculus semimembranosus), corner round (Musculus quadriceps femoris), roast beef (Musculus gluteus medius), tenderloin (Musculus psoas major) and loin (Musculus longissimus)) and tallow (subcutaneous fat) as described by Huuskonen (2014). The amount of tallow was evaluated by cutting off the visible subcutaneous fat on the surface of primal cuts and by weighing the yield of tallow in grams. All these cuttings were weighed automatically in the slaughter line and their yields were expressed as percentages of the carcass cold weight $(0.98 \times$ carcass hot weight, 50 min post mortem).

This dataset comprised 1112 slaughtered bulls and 260 heifers (Table 1). There was only one Ba heifer in this dataset so results are not shown for Ba heifers. The mean carcass gain in the commercial cutting data was 4 and $6 \%$ lower than that in the complete slaughter data for the bulls and heifers, respectively, but the average carcass weights as well as conformation and fat scores were almost the same in both datasets.

\section{Statistical methods}

The results of the complete slaughter data and commercial cuttings are shown as least squares means. The normality of residuals and the homogeneity of variances were checked using graphical methods: box-plots and scatter plots of residuals and fitted values. The data were subjected to the analysis of variance using the SAS Mixed procedure (version 9.3, SAS Institute Inc., Cary, NC). The model used was

$$
y_{i j}=m+\alpha_{i}+e_{i j}
$$

where $m$ is the overall mean, $e_{i j}$ is the random error term and $\alpha_{i}$ is the fixed effect of breed. Effects of slaughterhouse location and age at slaughter were not taking into consideration in the final statistical model because these effects were quantitatively minimal and they have no importance from a practical point of view. Differences between the breeds were compared using Tukey's $t$-test. $p$-values less than 0.05 are reported as statistically significant.

\section{Results}

The most common breeds in the complete dataset were $\mathrm{Hf}$ (6323 and 2385 observations for bulls and heifers, respectively), Ch (4421 and 1794), Li (4335 and 1951) and Ab (4068 and 1692), while Si (2152 and 774) and Ba (344 and 147) were less common. The average slaughter age for the Ch bulls (552 d) was clearly lower compared to the other breed groups $(p<0.001)$ (Table 2$)$. There were no differences in the slaughter ages among $\mathrm{Ab}, \mathrm{Ba}, \mathrm{Hf}$ and Li bulls. However, the Ab, $\mathrm{Hf}$ and Li bulls were 6,7 and 6 days younger than the Si bulls $(p<0.001)$, respectively. For heifers the average slaughter age ranged from 451 days for Ch to 475 days for Ba (Table 3).

$\mathrm{Ab}$ and $\mathrm{Hf}$ bulls had the lowest ( 619 and $618 \mathrm{~g} \mathrm{~d}^{-1}$, respectively) and Ch bulls the highest ( $724 \mathrm{~g} \mathrm{~d}^{-1}$ ) average daily carcass gain. Ba and Li bulls grew $7 \%$, Si bulls $11 \%$ and Ch bulls $17 \%$ faster compared to the British breeds $(p<0.001)$ (Table 2). In addition, Si bulls grew $4 \%$ and Ch bulls $9 \%$ faster compared to Ba and Li bulls $(p<0.001)$. Furthermore, Ch bulls grew $6 \%$ faster compared to Si bulls $(p<0.001)$. For heifers $\mathrm{Hf}$ had the lowest daily carcass gain $\left(468 \mathrm{~g} \mathrm{~d}^{-1}\right)$. $\mathrm{Ab}$ heifers grew $2 \%, \mathrm{Ba}$, Li and Si heifers $8 \%$ and $\mathrm{Ch}$ heifers $15 \%$ faster compared to $\mathrm{Hf}$ heifers $(p<0.001)$. Carcass weights of the bulls ranged from $368 \mathrm{~kg}$ for $\mathrm{Ab}$ and $\mathrm{Hf}$ to $413 \mathrm{~kg}$ for Ch. Respectively for heifers, carcass weight ranged from $232 \mathrm{~kg}$ for $\mathrm{Hf}$ to $255 \mathrm{~kg}$ for $\mathrm{Ch}$. In general, British beef breeds produced lighter weight carcasses than Continental beef breeds (Tables 2 and 3).

The EUROP conformation score was lowest for Ab (6.95) and Hf (6.87) bulls. Ba, Ch, Li and Si bulls produced 49, $35,41$ and $20 \%$ better conformed carcasses compared to British breeds, respectively $(p<0.001)$ (Table 2$)$. Also all Continental breeds differed significantly from each other for conformation score $(p<0.001)$. For heifers, carcass conformation score ranged from 5.12 for $\mathrm{Hf}$ to 7.73 for $\mathrm{Ba}$, and all breeds differed significantly from each other $(p<0.001)$ (Table 3). 
Table 2. Carcass gain, carcass characteristics and valuable cuts of Aberdeen Angus (Ab), Blonde d'Aquitaine (Ba), Charolais (Ch), Hereford (Hf), Limousin (Li) and Simmental (Si) bulls in Finnish slaughter dataset. Between-breeds comparisons (Tukey, $p<0.05$ ): estimated means with the different letters were significantly different $(p<0.05)$.

\begin{tabular}{|c|c|c|c|c|c|c|c|c|}
\hline & \multicolumn{5}{|c|}{ Breed } & \multirow[b]{2}{*}{$\mathrm{Si}$} & \multirow[t]{2}{*}{ SEM } & \multirow[t]{2}{*}{$p$-value } \\
\hline & $A b$ & $\mathrm{Ba}$ & $\mathrm{Ch}$ & $\mathrm{Hf}$ & $\mathrm{Li}$ & & & \\
\hline \multicolumn{9}{|c|}{ Dataset, complete slaughter data } \\
\hline Number of animals & 4068 & 344 & 4421 & 6323 & 4335 & 2152 & - & - \\
\hline Age at slaughter, d & $571^{a}$ & $570^{\mathrm{ab}}$ & $552^{c}$ & $572^{a}$ & $571^{\mathrm{a}}$ & $565^{b}$ & 3.1 & $<0.001$ \\
\hline Carcass gain, $\mathrm{g} \mathrm{d}^{-1}$ & $619^{a}$ & $663^{b}$ & $724^{c}$ & $618^{a}$ & $660^{b}$ & $686^{d}$ & 5.7 & $<0.001$ \\
\hline Carcass weight, kg & $368^{a}$ & $393^{b}$ & $413^{c}$ & $368^{a}$ & $391^{b}$ & $402^{d}$ & 3.2 & $<0.001$ \\
\hline Conformation & $6.95^{\mathrm{a}}$ & $10.27^{b}$ & $9.31^{c}$ & $6.87^{a}$ & $9.71^{d}$ & $8.30^{\mathrm{e}}$ & 0.103 & $<0.001$ \\
\hline Fat score & $3.29^{a}$ & $1.75^{b}$ & $2.25^{c}$ & $3.25^{d}$ & $2.19^{e}$ & $2.31^{f}$ & 0.044 & $<0.001$ \\
\hline \multicolumn{9}{|c|}{ Dataset, commercial cutting } \\
\hline Number of animals & 178 & 11 & 196 & 288 & 286 & 153 & - & - \\
\hline Age at slaughter, d & $578^{a}$ & $570^{a b c}$ & $564^{\mathrm{ab}}$ & $564^{b}$ & $597^{c}$ & $566^{a b}$ & 15.7 & $<0.001$ \\
\hline Carcass gain, g d & $568^{a}$ & $618^{a b}$ & $710^{c}$ & $562^{a}$ & $653^{b}$ & $667^{b}$ & 30.2 & $<0.001$ \\
\hline Carcass weight, kg & $344^{\mathrm{a}}$ & $367^{a}$ & $415^{b}$ & $332^{\mathrm{a}}$ & $405^{b c}$ & $392^{c}$ & 17.4 & $<0.001$ \\
\hline Conformation & $6.51^{\mathrm{a}}$ & $9.73^{b c}$ & $9.21^{b}$ & $6.39^{a}$ & $9.77^{c}$ & $7.91^{\mathrm{e}}$ & 0.523 & $<0.001$ \\
\hline Fat score & $3.08^{\mathrm{a}}$ & $2.18^{\mathrm{b}}$ & $2.37^{b}$ & $2.88^{\mathrm{c}}$ & $2.38^{b}$ & $2.36^{\mathrm{b}}$ & 0.232 & $<0.001$ \\
\hline \multicolumn{9}{|l|}{ From carcass yield, $\mathrm{g} \mathrm{kg}^{-1}$} \\
\hline Subcutaneous fat & $54.6^{\mathrm{a}}$ & $25.0^{\mathrm{bd}}$ & $37.0^{\mathrm{b}}$ & $49.7^{c}$ & $31.4^{d}$ & $37.0^{\mathrm{b}}$ & 4.66 & $<0.001$ \\
\hline M. longissimus & $37.3^{\mathrm{a}}$ & $41.4^{\mathrm{bcd}}$ & $42.2^{b}$ & $38.5^{c}$ & $44.2^{d}$ & $41.3^{b}$ & 1.15 & $<0.001$ \\
\hline M. psoas major & $13.5^{\mathrm{a}}$ & $16.2^{b}$ & $14.7^{c}$ & $13.4^{\mathrm{a}}$ & $15.0^{c}$ & $14.7^{c}$ & 0.40 & $<0.001$ \\
\hline M. semimembranosus & $36.2^{\mathrm{a}}$ & $45.0^{b}$ & $40.9^{c}$ & $37.7^{d}$ & $43.8^{b}$ & $41.0^{c}$ & 1.28 & $<0.001$ \\
\hline M. semitendinosus & $59.6^{a}$ & $71.7^{b}$ & $66.9^{c}$ & $61.4^{d}$ & $71.4^{b}$ & $65.4^{c}$ & 1.75 & $<0.001$ \\
\hline M. quadriceps femoris & $33.9^{a}$ & $39.0^{\mathrm{bc}}$ & $36.5^{\text {be }}$ & $35.2^{d}$ & $37.7^{c}$ & $36.0^{\text {de }}$ & 0.94 & $<0.001$ \\
\hline M. gluteus medius & $16.9^{a}$ & $21.4^{\mathrm{b}}$ & $19.8^{\mathrm{bc}}$ & $17.3^{\mathrm{a}}$ & $19.9^{\mathrm{bc}}$ & $19.1^{c}$ & 0.57 & $<0.001$ \\
\hline
\end{tabular}

SEM = standard error of the mean; Conformation score: (1 = poorest, 15 = excellent); Fat score: ( 1 = leanest, 5 = fattest); Musculus longissimus = loin; Musculus psoas major = tender loin; Musculus semimembranosus = inside round; Musculus semitendinosus = outside round; Musculus quadriceps femoris = corner round; Musculus gluteus medius = roast beef

The fat score was lowest for $\mathrm{Ba}$ (1.75) and highest for Ab bulls (3.29). Ab, Ch, Hf, Li and Si bulls produced 88, 29, 86,25 and $32 \%$ fatter carcasses compared to Ba bulls, respectively $(p<0.001)$. All breeds differed significantly from each other for carcass fat score (Table 2). For heifers, carcass fat score was lowest for Ba (2.27) and highest for $\mathrm{Ab}(3.88)$ and $\mathrm{Hf}$ (3.89) breeds. Ab and $\mathrm{Hf}$ heifers had $71 \%$, Ch and Li heifers $30 \%$ and $\mathrm{Si}$ heifers $34 \%$ higher fat score compared to Ba heifers $(P<0.001)$. In addition, $\mathrm{Ab}$ and $\mathrm{Hf}$ heifers had $33 \%(p<0.001)$ and $\mathrm{Si}$ heifers $4 \%$ $(p<0.01)$ higher fat score compared to $\mathrm{Ch}$ and Li heifers. Furthermore, Ab and $\mathrm{Hf}$ heifers had $28 \%$ higher fat score compared to Si heifers $(p<0.001)$.

Breed had clear effects on the yield of valuable cuts. In general, Continental breeds produced higher yields of valuable cuttings (loins, rounds) and less subcutaneous fat than British breeds (Tables 2 and 3 ). In comparing British breeds the yield of subcutaneous fat was significantly lower in the $\mathrm{Hf}$ than in the Ab bulls and heifers $(p<0.05)$. The yields of loin $(p<0.01)$, inside round $(p<0.01)$, outside round $(p<0.01)$ and corner round $(p<0.001)$ were higher in the $\mathrm{Hf}$ bulls compared to the Ab bulls (Table 2). Furthermore, the yields of loin and corner round $(p<0.05)$ were higher in the $\mathrm{Hf}$ heifers compared to the Ab heifers $(p<0.05)$.

In comparing Continental breed bulls Ba and Li seemed to achieve the highest percentage of many valuable cuttings. For example, the yields of inside round and outside round were significantly higher in the Ba and Li bulls compared to the Ch and Si bulls (Table 2). Additionally, the yield of tender loin was higher in the Ba bulls compared to the Ch, Li and Si bulls. Furthermore, the yield of loin was higher in the Li bulls compared to the Ch and Si bulls. The carcasses of the Li bulls contained less subcutaneous fat than the carcasses of the Ch and Si bulls. Looking at the heifers there were no significant differences in the yield of subcutaneous fat among $\mathrm{Ch}$, Li and Si breeds. 
Table 3. Carcass gain, carcass characteristics and valuable cuts of Aberdeen Angus (Ab), Blonde d'Aquitaine (Ba), Charolais (Ch), Hereford (Hf), Limousin (Li) and Simmental (Si) heifers in Finnish slaughter dataset. Between-breeds comparisons (Tukey, $p<0.05$ ): estimated means with the different letters were significantly different $(p<0.05)$.

\begin{tabular}{|c|c|c|c|c|c|c|c|c|}
\hline & \multicolumn{5}{|c|}{ Breed } & \multirow{2}{*}{\multicolumn{2}{|c|}{ SEM }} & \multirow[t]{2}{*}{$p$-value } \\
\hline & $A b$ & $\mathrm{Ba}$ & $\mathrm{Ch}$ & $\mathrm{Hf}$ & $\mathrm{Li}$ & & & \\
\hline \multicolumn{9}{|c|}{ Dataset, complete slaughter data } \\
\hline Number of animals & 1692 & 147 & 1794 & 2385 & 1951 & 774 & - & - \\
\hline Age at slaughter, d & $458^{a}$ & $475^{b}$ & $451^{c}$ & $465^{d}$ & $469^{b}$ & $453^{c}$ & 4.4 & $<0.001$ \\
\hline Carcass gain, $\mathrm{g} \mathrm{d}^{-1}$ & $478^{a}$ & $500^{\mathrm{b}}$ & $538^{c}$ & $468^{d}$ & $504^{b}$ & $510^{\mathrm{b}}$ & 6.8 & $<0.001$ \\
\hline Carcass weight, kg & $233^{a}$ & $252^{\mathrm{bc}}$ & $255^{b}$ & $232^{a}$ & $250^{c}$ & $244^{d}$ & 3.1 & $<0.001$ \\
\hline Conformation & $5.27^{\mathrm{a}}$ & $7.73^{b}$ & $6.53^{c}$ & $5.12^{d}$ & $7.18^{\mathrm{e}}$ & $5.72^{f}$ & 0.116 & $<0.001$ \\
\hline Fat score & $3.88^{a}$ & $2.27^{\mathrm{b}}$ & $2.94^{c}$ & $3.89^{a}$ & $2.93^{c}$ & $3.04^{d}$ & 0.074 & $<0.001$ \\
\hline \multicolumn{9}{|c|}{ Dataset, commercial cutting } \\
\hline Number of animals & 69 & - & 31 & 29 & 94 & 37 & - & - \\
\hline Age at slaughter, $d$ & $457^{a}$ & - & $494^{b}$ & $510^{\mathrm{b}}$ & $489^{b}$ & $503^{b}$ & 8.2 & $<0.001$ \\
\hline Carcass gain, $\mathrm{g} \mathrm{d}^{-1}$ & $449^{a}$ & - & $511^{\mathrm{b}}$ & $417^{a}$ & $489^{b}$ & $450^{\mathrm{a}}$ & 13.0 & $<0.001$ \\
\hline Carcass weight, kg & $219^{a}$ & - & $266^{b}$ & $228^{\mathrm{ac}}$ & $253^{\text {bd }}$ & $242^{\text {cd }}$ & 5.8 & $<0.001$ \\
\hline Conformation & $5.46^{\mathrm{a}}$ & - & $7.00^{\mathrm{b}}$ & $5.17^{a}$ & $7.70^{c}$ & $5.41^{\mathrm{a}}$ & 0.227 & $<0.001$ \\
\hline Fat score & $3.96^{\mathrm{a}}$ & - & $2.90^{b}$ & $3.69^{a}$ & $2.84^{b}$ & $3.16^{b}$ & 0.148 & $<0.001$ \\
\hline \multicolumn{9}{|l|}{ From carcass yield, $\mathrm{g} \mathrm{kg}^{-1}$} \\
\hline Subcutaneous fat & $85.7^{a}$ & - & $48.7^{b}$ & $71.7^{c}$ & $46.1^{\mathrm{b}}$ & $55.5^{b}$ & 3.61 & $<0.001$ \\
\hline M. longissimus & $37.6^{a}$ & - & $44.1^{\mathrm{bc}}$ & $39.9^{d}$ & $45.9^{c}$ & $42.7^{b}$ & 0.71 & $<0.001$ \\
\hline M. psoas major & $14.4^{\mathrm{a}}$ & - & $16.1^{\mathrm{b}}$ & $14.3^{\mathrm{a}}$ & $16.4^{b}$ & $16.0^{\mathrm{b}}$ & 0.25 & $<0.001$ \\
\hline M. semimembranosus & $38.6^{a}$ & - & $45.9^{b}$ & $40.6^{a}$ & $48.6^{c}$ & $45.0^{b}$ & 0.80 & $<0.001$ \\
\hline M. semitendinosus & $56.9^{a}$ & - & $68.6^{\mathrm{b}}$ & $59.2^{\mathrm{a}}$ & $72.5^{c}$ & $64.1^{d}$ & 1.01 & $<0.001$ \\
\hline M. quadriceps femoris & $36.1^{\mathrm{a}}$ & - & $41.4^{b c}$ & $38.4^{d}$ & $41.9^{c}$ & $39.3^{\mathrm{bd}}$ & 0.67 & $<0.001$ \\
\hline M. gluteus medius & $16.8^{\mathrm{a}}$ & - & $21.3^{b c}$ & $17.9^{a}$ & $21.3^{\mathrm{b}}$ & $20.0^{c}$ & 0.43 & $<0.001$ \\
\hline
\end{tabular}

SEM = standard error of the mean; Conformation: (1 = poorest, 15 = excellent); Fat cover: (1 = leanest, 5 = fattest)

Average carcass weights in different EUROP fat score classes and the incidence of different fat scores in breed groups are presented in Table 4. The most common fat class for $\mathrm{Ba}, \mathrm{Ch}$, Li and Si bulls was fat score 2, including 52, 58, 58 and 54\% of all observations within breed group, respectively. For Ab and $\mathrm{Hf}$ bulls fat score 3 incidence was greater than score 2, being 40 and $41 \%$, respectively. Considering fat score $4,32 \%$ of $\mathrm{Ab}$ and $\mathrm{Hf}$ bulls were placed to this category. For other breed groups, only $2-5 \%$ of bulls ranked to class 4 . In addition, 8-9\% of $\mathrm{Ab}$ and $\mathrm{Hf}$ carcasses, but less than $1 \%$ carcasses for other breed groups were placed to fat score 5 . In general, the average carcass weight of the Continental breed bulls in different fat score classes was higher than that of the British breed bulls (Table 4). For example, in fat score 3 the average carcass weights were 12, 18, 12 and $15 \%$ higher with $\mathrm{Ba}, \mathrm{Ch}$, Li and Si bulls, respectively, compared to Ab and Hf bulls $(p<0.001)$.

For heifers the most common fat class for Ch, Li and Si breeds was fat score 3, including 45, 41 and $51 \%$ of all observations, respectively. For $\mathrm{Ab}$ and $\mathrm{Hf}$ heifers the most common fat class was 4, including 43 and $41 \%$ of all observations. On the contrary, $48 \%$ of the Ba heifers were ranked as fat score 2 . Even $27-28 \%$ of $\mathrm{Ab}$ and $\mathrm{Hf}$ heifers, but less than $4 \%$ heifers for other breed were placed to fat score 5 (Table 4). As well as the bulls, the average carcass weight of the Continental breed heifers in different fat score classes was higher than that of the British breeds. For example, in fat score 3 the average carcass weights were 27, 22, 18 and 14\% higher with Ba, Ch, Li and Si heifers, respectively, compared to $\mathrm{Ab}$ and $\mathrm{Hf}$ heifers $(p<0.001)$.

For $\mathrm{Ab}, \mathrm{Hf}$ and $\mathrm{Si}$ bulls, the majority of carcasses $(63,62$ and $63 \%$, respectively) were placed to conformation scores $7(\mathrm{R}-)$ to $9(\mathrm{R}+)$, and the most common conformation class was R- (32, 33 and 23\% of all observations for $\mathrm{Ab}, \mathrm{Hf}$ and Si bulls, respectively) (data not shown). For Si bulls $22 \%$ of carcasses, but only $3 \%$ carcasses of $\mathrm{Ab}$ and $\mathrm{Hf}$ bulls, were placed better than score $9(\mathrm{R}+)$. Instead, for Ba, Ch and Li bulls 53,43 and $47 \%$ of the carcasses conformed better than score $\mathrm{R}+$, respectively. Considering the most common conformation classes (6-12), the average carcass weights of $\mathrm{Ba}$ and $\mathrm{Li}$ bulls were generally lower compared to Ab, Ch, $\mathrm{Hf}$ and Si bulls (data not shown). In other words, Ba and Li bulls were classified better than other breed groups in the same carcass weight. 
Table 4. Average carcass weights of Aberdeen Angus (Ab), Blonde d'Aquitaine (Ba), Charolais (Ch), Hereford (Hf), Limousin (Li) and Simmental (Si) bulls and heifers in different EUROP fat score classes $(1=$ leanest, 5 = fattest). Between-breeds comparisons (Tukey, $p<0.05)$ : estimated means with the different letters were significantly different $(p<0.05)$.

\begin{tabular}{|c|c|c|c|c|c|c|c|c|}
\hline & \multicolumn{6}{|c|}{ Breed } & \multirow[t]{2}{*}{ SEM } & \multirow[t]{2}{*}{$p$-value } \\
\hline & $A b$ & $\mathrm{Ba}$ & $\mathrm{Ch}$ & $\mathrm{Hf}$ & $\mathrm{Li}$ & Si & & \\
\hline \multicolumn{9}{|l|}{ Bulls } \\
\hline Total, $\mathrm{n}$ & 4068 & 344 & 4421 & 6323 & 4335 & 2152 & - & - \\
\hline Fat score & \multicolumn{8}{|c|}{$\mathrm{n}$ (observations/fat score) } \\
\hline 1 & 91 & 129 & 457 & 160 & 607 & 216 & - & - \\
\hline 2 & 675 & 178 & 2583 & 1071 & 2499 & 1166 & - & - \\
\hline 3 & 1630 & 30 & 1220 & 2598 & 1039 & 663 & - & - \\
\hline 4 & 1322 & 7 & 148 & 2019 & 178 & 102 & - & - \\
\hline 5 & 350 & - & 13 & 475 & 12 & 5 & - & - \\
\hline Fat score & \multicolumn{6}{|c|}{ Carcass weight $(\mathrm{kg})$ in different fat score classes } & & \\
\hline 1 & $244^{a}$ & $371^{\mathrm{b}}$ & $362^{\mathrm{b}}$ & $224^{c}$ & $342^{\mathrm{d}}$ & $351^{\mathrm{d}}$ & 7.4 & $<0.001$ \\
\hline 2 & $331^{\mathrm{a}}$ & $406^{b}$ & $409^{b}$ & $326^{a}$ & $391^{c}$ & $395^{c}$ & 4.4 & $<0.001$ \\
\hline 3 & $366^{\mathrm{a}}$ & $412^{\mathrm{bc}}$ & $435^{d}$ & $369^{a}$ & $412^{\mathrm{b}}$ & $424^{c}$ & 8.8 & $<0.001$ \\
\hline 4 & $388^{\mathrm{a}}$ & $400^{\mathrm{a}}$ & $456^{b}$ & $391^{\text {a }}$ & $434^{c}$ & $447^{b}$ & 16.5 & $<0.001$ \\
\hline 5 & $406^{\mathrm{a}}$ & - & $446^{b}$ & $410^{\mathrm{a}}$ & $422^{\mathrm{ab}}$ & $452^{\mathrm{b}}$ & 19.8 & 0.002 \\
\hline \multicolumn{9}{|l|}{ Heifers } \\
\hline Total, $\mathrm{n}$ & 1692 & 147 & 1794 & 2385 & 1951 & 774 & - & - \\
\hline Fat score & \multicolumn{8}{|c|}{ n (observations/fat score) } \\
\hline 1 & 17 & 25 & 68 & 19 & 69 & 21 & - & - \\
\hline 2 & 112 & 71 & 476 & 169 & 570 & 156 & - & - \\
\hline 3 & 384 & 40 & 807 & 541 & 804 & 393 & - & - \\
\hline 4 & 728 & 9 & 388 & 984 & 443 & 177 & - & - \\
\hline 5 & 451 & 2 & 55 & 672 & 65 & 27 & - & - \\
\hline Fat score & \multicolumn{6}{|c|}{ Carcass weight $(\mathrm{kg})$ in different fat score classes } & & \\
\hline 1 & $97^{\mathrm{a}}$ & $231^{b}$ & $184^{c}$ & $141^{\mathrm{d}}$ & $192^{c}$ & $165^{\mathrm{e}}$ & 9.6 & $<0.001$ \\
\hline 2 & $178^{\mathrm{a}}$ & $246^{\mathrm{b}}$ & $230^{c}$ & $180^{\mathrm{a}}$ & $236^{d}$ & $220^{e}$ & 3.9 & $<0.001$ \\
\hline 3 & $215^{\mathrm{a}}$ & $271^{\mathrm{b}}$ & $262^{c}$ & $212^{\mathrm{a}}$ & $253^{d}$ & $245^{e}$ & 4.6 & $<0.001$ \\
\hline 4 & $237^{\mathrm{a}}$ & $267^{\mathrm{bc}}$ & $279^{b}$ & $235^{\mathrm{a}}$ & $267^{c}$ & $268^{c}$ & 9.2 & $<0.001$ \\
\hline 5 & $259^{\mathrm{a}}$ & $294^{\mathrm{bc}}$ & $303^{b}$ & $259^{a}$ & $280^{c}$ & $282^{\mathrm{c}}$ & 20.9 & $<0.001$ \\
\hline
\end{tabular}

SEM = standard error of the mean.

\section{Discussion}

The six breeds analyzed in the present study are the most common beef breeds used in Finland. Typically beef breed bulls and heifers are housed and fed consistently in finishing farms, i.e. different methods are not used for different breed groups within a finishing farm. Therefore, it can be assumed that the results of the present data give a good representation of the differences between the breed groups in Finnish cattle population.

Beef breeds can be classified by their growth rate in three different classes. Angus is classified as early maturing, $\mathrm{Hf}$ as medium maturing and $\mathrm{Ba}, \mathrm{Ch}$, Li and $\mathrm{Si}$ as late maturing breeds (Phillips 2010). As expected, considerable variation was observed among these six breeds for carcass gain and carcass traits in the present study. Consistent with the literature (Wulf et al. 1996, Barton and Pleasants 1997, Subrt and Divis 2002, Sami et al. 2004, Alberti et al. 2008) the carcass gain, carcass weight and conformation score were significantly higher in Continental breeds (Ba, Ch, Li, Si) compared to British breeds (Ab, Hf). However, it has been observed in some experiments that the carcass gain has been higher (or similar) in earlier maturing breeds than in later maturing breeds (Chambaz et al. 2003, Bartoň et al. 2006, Holló et al. 2012). Overall, it is difficult to make direct comparisons between the present field data and earlier experiments because in a single experiment an individual factor (e.g. slaughter age, carcass weight, intramuscular fat content) could be used as the end point of the study. Limitation of the present field data is that the breed effects are partly confounded with, for example, carcass weight. However, the observed carcass weights are nowadays the average weights for slaughtered bulls of these breeds in Finland, and therefore, the present results are valid from a practical point of view. 
According to Gregory et al. (1994) the $\mathrm{Ab}$ and $\mathrm{Hf}$ breeds were earlier maturing compared to $\mathrm{Ch}$, $\mathrm{Li}$ or $\mathrm{Si}$ breeds. Earlier maturing cattle should reach the optimal carcass maturity earlier than the later maturing cattle type. However, in the present Finnish dataset the earlier maturing Ab and $\mathrm{Hf}$ animals had the highest

slaughter age and the lowest slaughter weight. The higher slaughter age in Ab and $\mathrm{Hf}$ is in contrary to some previous studies in which different breeds and cattle types were slaughtered in similar end point e.g. back fat (Gregory et al. 1994), intramuscular fat content (Chambaz et al. 2003) or slaughter weight (Holló et al. 2012). In these studies the earlier maturing breeds reached the slaughter end point earlier than the later maturing breeds. However, in Finnish farms also British breeds are slaughtered at heavy carcass weights due to the falling supply of domestic beef and the pricing scheme that favours heavier animals (Herva et al. 2011).

Growth type has the potential to influence carcass composition by altering the relative growth patterns of muscle, bone and fat (Berg and Butterfield 1968, Priyanto et al. 1999). Carcass composition varies among cattle growth types (Koch et al. 1976, 1979, 1982, Stiffler et al. 1985, Griffin et al. 1992). It is important to understand how various cattle types can optimally produce lean, high-quality beef (May et al. 1992).

European Continental breeds developed on a high plane of nutrition typically have higher yields of edible product than British breeds (Koch and Dikeman 1977, Koch et al. 1979, 1982). Differences in beef growth types can be reflected in differences among breeds. The increased emphasis on selection for size has resulted in a broad array of growth types within most breeds (Brown et al. 2005). In the European market, carcasses are valued by conformation. In our dataset the conformation score was higher in late maturing $\mathrm{Ba}$, $\mathrm{Li}$, Si and Ch breeds than in earlier maturing Angus and Hereford. Also Bartoň et al. (2006) and Holló et al. (2012) reported a significantly better conformation for Ch and Si bulls in comparison with the British breeds.

In the present dataset almost all valuable cuts were greater in the Continental breeds than in British breeds. These results are supported, for example, by data of Miller et al. (1996) and Arthur et al. (1995) who reported larger foreshank in the large-late maturing Brown Swiss and Ch breeds when these breeds were compared to breeds of earlier maturing and medium size. Also Koch et al. (1976) stated that large-framed Ch, Li and Si crosses had higher percentages of retail product than medium framed Hf-Ab crosses. Further, Bartoň et al. (2006) observed that the retail product yield was significantly higher in $\mathrm{Ch}$ and $\mathrm{Si}$ bulls than in $\mathrm{Ab}$ and $\mathrm{Hf}$ bulls.

Estimate of the fat cover can be used commercially to select animals for slaughter. In Finnish production system excess fat cover is penalized by heavy deductions in the carcass price. In agreement with the present results, Gregory et al. (1994) reported that Angus and Hereford breeds had consistently more subcutaneous fat thickness compared to $\mathrm{Ch}$, Li and Si breeds. The greater amount of subcutaneous fat of Ab and Hf carcasses can be seen in our dataset both in the EUROP classification and in the proportion of dissected fat in commercial cutting. These results are supported with the earlier studies of Bartoň et al. (2006) and Holló et al. (2012).

In accordance with our results, Schenkel et al. (2004) reported with purebred beef bulls that Ba showed the least back fat thickness, followed by $\mathrm{Li}$, Ch and $\mathrm{Si}$ when breed differences for growth and body composition traits were studied in Ontario bull test stations from 1991 to 2000. In that case, the Hf bulls had the highest level and the Ab bulls the second highest level of back fat thickness (Schenkel et al. 2004). Also Bartoň et al. (2006) concluded that, in general, the animals of earlier maturing breeds $(\mathrm{Hf}, \mathrm{Ab})$ produced relatively more fat than later maturing $(\mathrm{Ch}, \mathrm{Si})$ in spite of the fact that they were slaughtered at a significantly lower live weight. This is in agreement also with the findings reported here.

The decrease in the number of dairy cows has reduced the number of dairy breed calves available for beef production in Finland and while the beef cow herd has increased (Niemi and Ahlstedt 2014), it is not sufficient to offset the fall in the dairy cow number. Consequently, if beef output is to be maintained, carcass weights must increase. However, increasing carcass weight with the present breed distribution is not desirable, as beef carcasses are already adequately fat or over-fat at existing carcass weights (Herva et al. 2011). Also the feed efficiency in beef production decreases with prolonged growing period due to increased maintenance energy requirements and increased fatness (e.g. Manni et al. 2013). One approach to increase beef carcass weights without a subsequent increase in fatness is through a change in breed distribution. According to the present data the $\mathrm{Ab}$ and $\mathrm{Hf}$ bulls would obtain carcass fat class 3 at carcass weights of ca. 366-369 kg but late maturing Continental breeds at carcass weights of ca. $412-435 \mathrm{~kg}$. Thus the use of late maturing rather than early maturing breeds would permit carcass weight of the progeny to increase 13-19\% without an increase in carcass fatness. However, the decision to opt for a breed depends not only on the growth performance and carcass characteristics but also on the other aspects affecting the beef production. It is stated, for example, that Angus $\times$ Hereford beef cows tend to be lighter, their diet energy demand is less and maintaining body condition score is more stable than in breeds of European 
Continental origin (Freetly et al. 2001, Arango et al. 2002). The lifetime productivity measured with number of matings per cow, calves weaned per cow exposed and calf weight weaned per cow exposed is significantly higher for Angus $\times$ Hereford crossbred dams than for other straight breeds or crossbreds in extensive cow-calf production environment/systems (Davis et al. 1994). The one possible way by which carcass weight can increase without a subsequent increase in fatness is to inseminate dairy cows with semen derived from beef cattle if the calves are not to be used as replacement animals on the dairy farm. For example, Huuskonen et al. $(2013,2014)$ concluded that crossbreeding with Continental beef breeds ( $\mathrm{Ba}, \mathrm{Ch}, \mathrm{Li}, \mathrm{Si}$ ) had favourable effects both on daily carcass gain and carcass quality traits of the progeny when compared with purebred dairy bulls.

\section{Conclusions}

In conclusion, significant breed differences were observed in growth performance, carcass traits and retail product yield. The later maturing, Continental beef breeds seem to reach higher carcass gains, produce less fat and have more valuable cuts than the earlier maturing British beef breeds. The later maturing beef breeds tend to have carcass traits that suit well in the Finnish beef production system.

\section{Acknowledgements}

Financial support from the Centre for Economic Development, Transport and the Environment for Northern Ostrobothnia, A-Tuottajat Ltd., HK-Agri Ltd., Saarioinen Lihanjalostus Ltd., Snellman Lihanjalostus Ltd. and Oiva Kuusisto Foundation is gratefully acknowledged. We would like to thank Ms. Maarit Hyrkäs for the data processing and statistical analyses. The evaluation of the manuscript by Professor Marketta Rinne is warmly acknowledged.

\section{References}

Åkerlind, M., Nielsen, N.I. \& Volden, H. 2011. Animal input characteristics. In: Volden, H. (ed.). NorFor - The Nordic feed evaluation system. Wageningen: Wageningen Academic Publishers. p. 27-32.

Alberti, P., Panea, B., Sañudo, C., Olleta, J.L., Ripoll, G., Ertbjerg, P., Christensen, M., Gigli, S., Failla, S., Concetti, S., Hocquette, J.F., Jailler, R., Rudel, S., Renend, G., Nute, G.R., Richardson, R.I. \& Williams, J.L. 2008. Live weight, body size and carcass characteristics of young bulls of fifteen European breeds. Livestock Science 114: 19-30.

Arango, J.A., Cundiff, L.V. \& Van Vleck, L.D. 2002. Breed comparisons of Angus, Charolais, Hereford, Jersey, Limousin, Simmental, and South Devon for weight, weight adjusted for body condition score, height, and body condition score of cows. Journal of Animal Science 80: 3123-3132.

Arthur, P.F., Hearnshaw, H., Johnson, D. \& Stephenson, P.D. 1995. Evaluation of Angus, Charolais, and Hereford as terminal sire breeds of Hereford and first-cross cows. II. Carcass characteristics and retail yield of progeny. Australian Journal of Agricultural Research 46: 1245-1258.

Barton, R.A. \& Pleasants, A.B. 1997. Comparison of the carcass characteristics of steers of different breeds and pre-weaning environments slaughtered at 30 months of age. New Zealand Journal of Agricultural Research 40: 57-68.

Bartoň, L., Řehák, D., Teslík, V., Bureš, D. \& Zahrádková, R. 2006. Effect of breed on growth performance and carcass composition of Aberdeen Angus, Charolais, Hereford and Simmental bulls. Czech Journal of Animal Science 51: 47-53.

Berg, R.T. \& Butterfield, R.M. 1968. Growth patterns of bovine muscle, fat and bone. Journal of Animal Science 17: 611-619.

Brown Jr., A.H., Camfield, P.K., Johnson, Z.B., Rakes, L.Y., Pohlman, F.W., Brown, C.J., Sandelin, B.A. \& Baublits, R.T. 2005. Interaction of beef growth type $\times$ production system for carcass traits of steers. Asian-Australian Journal of Animal Science 18 : 259-266.

Chambaz, A., Scheeder, M.R.L., Kreuzer, M. \& Dufey, P.A. 2003. Meat quality of Angus, Simmental, Charolais and Limousin steers compared at the same intramuscular fat content. Meat Science 63: 491-500.

Cuvelier, C., Cabaraux, J.F., Dufrasne, I., Clinquart, A., Hocquette, J.F., Istasse, L. \& Hornick, J.-L. 2006a. Performance, slaughter characteristics and meat quality of young bulls from Belgian Blue, Limousin and Aberdeen Angus breeds fattened with a sugar -beet pulp or a cereal-based diet. Animal Science 82: 125-132.

Cuvelier, C., Clinquart, A., Hocquette, J.F., Cabaraux, J.F., Dufrasne, I., Istasse, L. \& Hornick, J.-L. 2006b. Comparison of composition and quality traits of meat from young finishing bulls from Belgian Blue, Limousin and Aberdeen Angus breeds. Meat Science 74: 522-531.

Davis, K.C., Tess, M.W., Kress, D.D., Doornbos, D.E. \& Anderson, D.C. 1994. Life cycle evaluation of five biological types of beef cattle in a cow-calf range production system: II. Biological and economical performance. Journal of Animal Science 72: 2591-2598.

EC 2006. Council Regulation (EC) No 1183/2006 of 24 July 2006 concerning the Community scale for the classification of carcasses of adult bovine animals. The Official Journal of the European Union L, 214: 1-6.

Freetly, H.C., Ferrell, C.L. \& Jenkins, T.G. 2001. Production performance of beef cows raised on three different nutritionally controlled heifer development programs. Journal of Animal Science 79: 819-826.

Gregory, K.E., Cundiff, L.V., Koch, R.M., Dikeman, M.E. \& Koohmaraie, M. 1994. Breed effects and retained heterosis for growth, carcass, and meat traits in advanced generations of composite populations of beef cattle. Journal of Animal Science 72: 833-850. 
Griffin, D.B., Savell, J.W., Morgan, J.B., Garret, R.P. \& Cross, H.R. 1992. Breed effects and retained heterosis for growth, carcass and meat traits in advanced generations of composite population of beef cattle. Journal of Animal Science 70: 2411-2430.

Herva, T., Huuskonen, A., Virtala, A.-M. \& Peltoniemi, O. 2011. On-farm welfare and carcass fat score of bulls at slaughter. Livestock Science 138: 159-166.

Herva, T., Virtala, A-M., Huuskonen, A., Saatkamp, H. W. \& Peltoniemi, O. 2009. On-farm welfare and estimated daily carcass gain of slaughtered bulls. Acta Agriculturae Scandinavica, Section A, Animal Science 59: 104-120.

Holló, G., Nuernberg, K., Somogyi, T., Anton, I. \& Holló, I. 2012. Comparison of fattening performance and slaughter value of local Hungarian cattle breeds to international breeds. Archiv Tierzucht 55: 1-12.

Huuskonen, A. 2014. A comparison of Nordic Red, Holstein-Friesian and Finnish native cattle bulls for beef production and carcass traits. Agricultural and Food Science 23: 159-164.

Huuskonen, A., Pesonen, M., Kämäräinen, H. \& Kauppinen, R. 2013. A comparison of purebred Holstein-Friesian and HolsteinFriesian $\times$ beef breed bulls for beef production and carcass traits. Agricultural and Food Science 22: 262-271.

Huuskonen, A., Pesonen, M., Kämäräinen, H. \& Kauppinen, R. 2014. Production and carcass traits of purebred Nordic Red and Nordic Red $\times$ beef breed crossbred bulls. Journal of Agricultural Science 152: 504-517.

Keane, M.G. \& Allen, P. 1998. Effects of production system intensity on performance, carcass composition and meat quality of beef cattle. Livestock Production Science 56: 203-214.

Koch, R.M. \& Dikeman, M.E. 1977. Characterization of biological types of cattle. V. Carcass wholesale cut composition. Journal of Animal Science 45: 30-42.

Koch, R.M., Dikeman, M.E., Allen, D.M., May, M., Crouse, J.A. \& Champion, D.R. 1976. Characterization of biological types of cattle. III. Carcass composition, quality, and palatability. Journal of Animal Science 43: 48-62.

Koch, R.M., Dikeman, M.E. \& Crouse, J.D. 1982. Characterization of biological types of cattle (cycle III). III. Carcass composition, quality, and palatability. Journal of Animal Science 54: 35-45.

Koch, R.M., Dikeman, M.E., Lipsey, R.J., Allen, D.M. \& Crouse, J.D. 1979. Characterization of biological types of cattle-cycle II. III. Carcass composition, quality, and palatability. Journal of Animal Science 49: 448-460.

Manni, K., Rinne, M., \& Huhtanen, P. 2013. Comparison of concentrate feeding strategies for growing dairy bulls. Livestock Science 152: 21-30.

May, S.C., Miles, W.L., Edwards, J.W., Williams, F.L., Wise, J.W., Morgan, J.B., Savell, J.W. \& Cross, H.R. 1992. Beef carcass composition of slaughter cattle differing in frame size, muscle score and external fatness. Journal of Animal Science 70: 2431-2445.

Miller, M.R., Ramsey, C.B., Claborn, S.W. \& Wu, C.K. 1996. Subprimal cutability and carcass value as effected by cattle type. Journal of Muscle Foods 7: 17-27.

Niemi, J. \& Ahlstedt, J. 2014. Finnish agriculture and rural industries 2014. MTT Agrifood Research Finland, Economic Research, Helsinki, Finland. Publications 115a. 97 p.

Pesonen, M., Honkavaara, M. \& Huuskonen, A. 2012. Effect of breed on production, carcass traits and meat quality of Aberdeen Angus, Limousin and Aberdeen Angus $\times$ Limousin bulls offered a grass silage-grain-based diet. Agricultural and Food Science 21: 361-369.

Pesonen, M., Honkavaara, M. \& Huuskonen, A. 2013a. Production, carcass and meat quality traits of Hereford, Charolais and HerefordxCharolais bulls offered grass silage-grain-based rations and slaughtered at high carcass weights. Acta Agriculturae Scandinavica, Section A, Animal Science 63: 28-38.

Pesonen, M., Honkavaara, M., Kämäräinen, H., Tolonen, T., Jaakkola, M., Virtanen, V. \& Huuskonen, A. 2013b. Effects of concentrate level and rapeseed meal supplementation on performance, carcass characteristics, meat quality and valuable cuts of Hereford and Charolais bulls offered grass silage-barley-based rations. Agricultural and Food Science 22: 151-167.

Phillips, C.J.C. 2010. Principles of cattle production. 2nd ed. Cambridge, UK: CABI Publications, Cambridge University Press . 233 p.

Priyanto, R., Johnson, E.R. \& Taylor, D.G. 1999. The economic importance of genotype in steers fed pasture or leucerne hay and prepared for the Australian and Japanese beef markets. New Zealand Journal of Agricultural Research 42: 393-404.

Sami, A.S., Augustini, C. \& Schwarz, F.J. 2004. Effect of feeding intensity and time on feed on performances, carcass characteristics and meat quality of Simmental bulls. Meat Science 67: 195-201.

Schenkel, F.S., Miller, S.P. \& Wilton, J.W. 2004. Genetic parameters and breed differences for feed efficiency, growth and body composition traits of young beef bulls. Canadian Journal of Animal Science 84: 177-185.

Stiffler, D.M., Griffin, C.M., Murphy, C.E., Smith, G.C. \& Savell, J.W. 1985. Characterization of cutability and palatability attributes among different slaughter groups of beef cattle. Meat Science 13: 167-182.

Subrt, J. \& Divis, V. 2002. The effect of individual Charolais sires on beef production of their crossbred progeny. Animal Science Papers and Reports 20: 25-32.

Wulf, D.M., Tatum, J.D., Green, R.D., Morgan, J.B., Golden, B.L. \& Smith, G.C. 1996. Genetic influences of beef longissimus palatability in Charolais- and Limousin-sired steers and heifers. Journal of Animal Science 74: 2394-2405. 